\title{
Screening for neonatal deafness in resource-poor countries: challenges and solutions
}

\author{
This article was published in the following Dove Press journal: \\ Research and Reports in Neonatology \\ 7 May 2015 \\ Number of times this article has been viewed
}

\section{Bolajoko O Olusanya}

Centre for Healthy Start Initiative, Ikoyi, Nigeria
Correspondence: Bolajoko O Olusanya Centre for Healthy Start Initiative, 286A Corporation Drive, Dolphin Estate, Ikoyi, Lagos, Nigeria

Tel +2348033344300

Email bolajoko.olusanya@uclmail.net

\begin{abstract}
Newborn or neonatal hearing screening (NHS) is offered routinely in high-income countries as an essential and mandatory intervention for the early detection of infants with permanent congenital or early-onset hearing loss. However, NHS is rarely offered presently in the vast majority of low- and middle-income countries, which account for over $80 \%$ of the incidence and burden of permanent congenital or early-onset hearing loss worldwide. This review provides an overview of the current status of NHS programs in the most developmentally disadvantaged low-and middle-income countries with a per capita income of approximately US\$6,000 or less against the backdrop of relevant recommendations for effective NHS programs. It highlights the key obstacles to the delivery and uptake of NHS services based on a review of available literature from the eligible countries. It proposes strategies for addressing these challenges and examines the crucial role of pediatricians and primary care physicians in providing leadership for the requisite multidisciplinary efforts to develop and promote effective NHS services in low- and middle-income countries.
\end{abstract}

Keywords: early detection, intervention, newborn screening, early childhood development, developing countries

\section{Introduction}

Annually, about 740,000 children (roughly six per 1,000 live births) have sensorineural hearing impairment in the first month of life in low- and middle-income countries (LMICs) compared with 28,000 (around two per 1,000 live births) in high-income countries. ${ }^{1-3}$ Available data from the World Health Organization (WHO) also suggest that approximately 7.5 million children below the age of 5 years have disabling ( $\geq 30 \mathrm{dBHL}$ ) hearing impairment worldwide, the vast majority (at least $80 \%$ ) of whom reside in LMICs. ${ }^{4,5}$ Without timely and appropriate intervention, these children are faced with a lifetime of speech and language difficulties and overall developmental deficits that place severe limitations on their educational and vocational attainments. ${ }^{6-9}$ In fact, untreated sensorineural hearing impairment in the first year of life has profound adverse consequences that transverse almost all developmental domains, manifesting in significant and often lifelong deficits in gross and fine motor skills, cognitive performance, speech and language development, and psychosocial development (Figure 1). ${ }^{10}$ Although the rates of emotional, intellectual, physical, and social development vary within each child and from child to child, a child with hearing impairment is faced with greater challenges than his/her normal hearing peers. The overall socioeconomic impact is substantial for the affected child, the family, and the community. ${ }^{10-12}$ For example, studies from high-income countries estimate the lifetime educational cost 


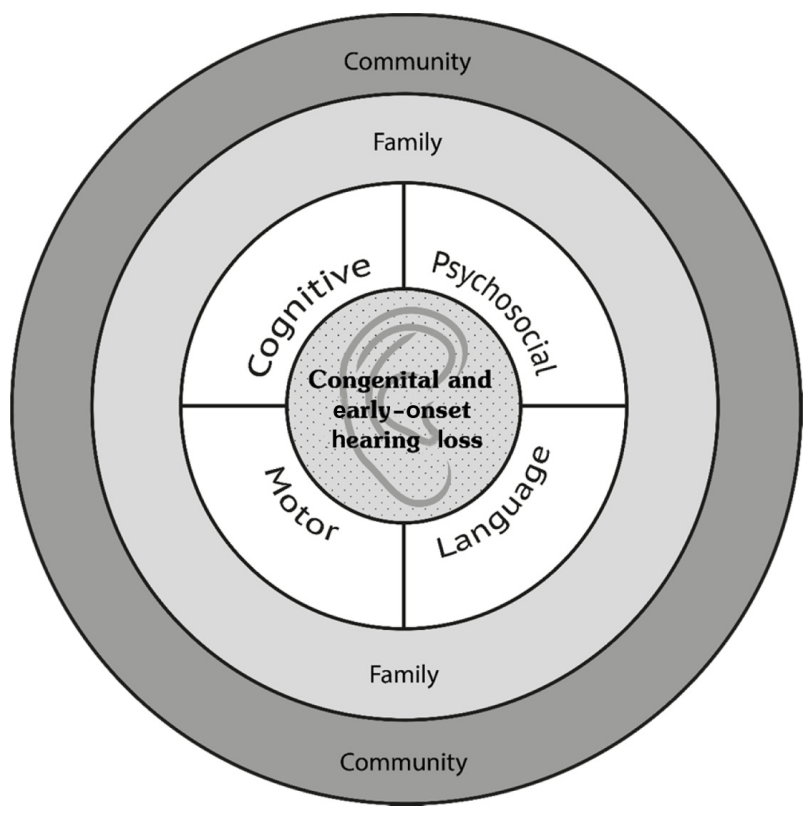

Figure I Dimensions of the societal impact of infant hearing loss.

of hearing loss at $\$ 115,600$ per child. ${ }^{12}$ Persons with speech disabilities are more often found to be unemployed or in a lower economic class than people with other disabilities, and the income for the hearing-impaired population is $40 \%-45 \%$ lower than for the hearing population. ${ }^{9}$

Perhaps the most robust scientific foundation for early hearing detection and intervention (EHDI) is encapsulated in the experimental evidence on human brain development. ${ }^{13,14}$ Auditory stimulation begins in utero and peaks around the sixth postnatal month, with the fastest growth occurring within the first 3 months. ${ }^{13}$ Intervention during this "critical" or "sensitive" period of rapid brain growth is characterized by neurogenesis, axonal and dendritic proliferation, synaptogenesis, cell apoptosis, synaptic pruning, and myelination with gliogenesis, and is often associated with the best possible outcomes. ${ }^{1,13}$ In fact, several studies have demonstrated that early detection of hearing loss through newborn or neonatal hearing screening (NHS) programs accompanied by timely provision of hearing devices by the first year of life is associated with significant developmental outcomes and substantial cost savings, ${ }^{15-22}$ although robust studies on the long-term economic benefits are still needed. ${ }^{23}$ Other benefits of EHDI are summarized in Table 1. ${ }^{1,24}$ In the absence of NHS, the age of detection is usually well over 24 months, and quite late for optimal outcomes in any population, even with the best of therapeutic intervention. ${ }^{25-27}$

The availability of simple, objective, and reliable hearing screening technologies such as otoacoustic emissions (OAE) and automated auditory brainstem response (AABR)
Table I Benefits of early detection of hearing impairment through newborn screening

- Provides timely information about a hidden and imminent disability

- Minimizes later misdiagnosis as a developmental delay rather than disability

- Associated conditions can be identified and managed more promptly

- Facilitates timely engagement of professional support

- Makes early intervention possible from 3 months of age

- Offers an essential gateway to normal development of the auditory system

- Facilitates the achievement of better speech and language outcomes

- Facilitates early commencement of other communication options

- Has better long-term benefits for the child, family, and community

has made EHDI feasible within the first 6 months of life. ${ }^{28,29}$ While universal hearing screening (UHS) is now a standard of care in virtually all high-income countries, this service is still not routinely provided in LMICs. ${ }^{30}$ This paper reviews the current challenges to NHS in LMICs based on available published reports and suggests approaches to extending the benefits of this intervention to affected families in resourcepoor nations.

\section{Definitions and data sources}

There is no consistent definition of "resource-poor", "resource-constrained", or "resource-limited" countries in the literature. The 139 countries classified as LMICs by the World Bank as of July 2014 have a per capita gross national income ranging from US\$150 to US\$12,745. In view of this wide range in income distribution and in order to focus on the most disadvantageous LMICs, the 91 countries with per capita gross national income of $\leq \mathrm{US} \$ 6,000$ as previously reported were selected. ${ }^{31}$ By world regions, 42 (46\%) countries are from Sub-Saharan Africa, 18 (20\%) from East Asia and the Pacific, ten (11\%) from Latin America and the Caribbean, eight (9\%) from the Middle East and North Africa, seven (8\%) from South Asia, and six (6\%) from Europe and Central Asia (see Table S1). ${ }^{31}$

The term "permanent congenital and early-onset hearing loss", or simply "hearing loss", is used more broadly to capture all degrees of hearing loss based on hearing threshold in the better ear averaged over frequencies $0.5,1,2$, and $4 \mathrm{kHz}$, classified as: mild (20-34 dBHL), moderate (35-49 dBHL), moderately severe (50-64 dBHL), severe (65-79 dBHL), and profound (80-94 dBHL). ${ }^{4}$

NHS studies published up until January 2015 were systematically retrieved from three major electronic databases, ie, PubMed, Scopus, and EMBASE. There was no restriction on article types in view of the limited publications from LMICs. 
Reference lists of retrieved articles were also perused for relevant reports. Separate searches were conducted for each of the 91 countries to maximize results using the search terms: "newborn hearing screening" AND "country name". Additional reports known to the author from prior research work on infant hearing loss were also included.

\section{Recommendations for implementation of NHS services}

Since its inception in 1969, the Joint Committee on Infant Hearing ( $\mathrm{JCIH})$ in the USA has led global efforts in formulating guidelines for EHDI through its periodic position statements. The pioneer professional associations of the JCIH were the American Speech Language Hearing Association, the then American Academy of Ophthalmology and Otolaryngology, and the American Academy of Pediatrics. Although JCIH jurisdiction was restricted to the USA, its guidelines have emerged as reference documents for other nations, including LMICs.

The current principles and core recommendations for EHDI, adapted from the JCIH 2007 Position Statement, ${ }^{32}$ are summarized in Figure 2. Adequate information about the screening tests should be offered to parents prior to conducting the tests. All newborns are expected to be screened in the first month of life, and those failing the screening tests evaluated for possible hearing loss by age 3 months with a battery of audiological and medical examinations. Patients who missed screening before hospital discharge and those delivered at home should be targeted for outpatient screening in the first month of life. Infants detected with hearing loss are expected to be enrolled in an intervention program by the age of 6 months. This program should consist of family counseling on the nature of the chosen intervention, further medical evaluation to determine the probable cause of hearing loss, as well as regular audiological support. Infants with established risk factors who pass the screening tests are expected to be placed under surveillance for possible late-onset hearing loss.

The screening technologies of choice are transient-evoked otoacoustic emissions (TEOAE), distortion product otoacoustic emissions (DPOAE), and AABR which can be used singly or in combination (OAE and AABR), especially for high-risk infants, including babies admitted to an intensive care unit. The TEOAE is a physiological test for measuring the integrity of the hearing function of the outer hair cells of the cochlea in response to audible sounds. During the test, clicks or tone bursts are presented to the ear through a lightweight probe that houses both a transducer and

\begin{tabular}{|c|c|c|c|c|}
\hline & Birth & Before one month & Before 3 months & Before 6 months \\
\hline Services & $\begin{array}{l}\text { Parental information } \\
\text { Educational leaflets and } \\
\text { clarification on } \\
\text { importance of newborn } \\
\text { hearing screening } \\
\text { Hospital-based inpatient } \\
\text { screening (OAE/AABR) } \\
\text { For all babies in NICU } \\
\text { and WBN }\end{array}$ & $\begin{array}{l}\text { Parental information } \\
\text { Educational leaflets and } \\
\text { clarifications on } \\
\text { importance of newborn } \\
\text { hearing screening } \\
\text { Outpatient screening } \\
\text { (OAE/AABR) } \\
\text { For home births and missed } \\
\text { or repeat inpatient screens }\end{array}$ & $\begin{array}{l}\text { Pediatric audiology } \\
\text { evaluation and diagnosis } \\
\text { - Child and family history } \\
\text { - Otoscopic inspection } \\
\text { - Middle ear function } \\
\text { - OAE } \\
\text { - ABR } \\
\text { - Frequency-specific tone } \\
\text { bursts } \\
\text { - Air and bone conduction } \\
\text { - Sedation capability }\end{array}$ & $\begin{array}{l}\text { Family counseling } \\
\text { Information on assistive listening } \\
\text { devices (eg, hearing aids, cochlear } \\
\text { implants) and other communication } \\
\text { options } \\
\text { Medical evaluations } \\
\text { (to determine etiology and identify } \\
\text { related conditions) } \\
\text { - Ophthalmologic } \\
\text { - Genetic } \\
\text { - Developmental assessment } \\
\text { Pediatric audiology support } \\
\text { - Behavioral response audiometry } \\
\text { - Hearing aid evaluation and } \\
\text { fitting } \\
\text { Ongoing monitoring including all } \\
\text { high-risk infants who passed the } \\
\text { screening tests }\end{array}$ \\
\hline
\end{tabular}

Figure 2 Recommended framework for early hearing detection and intervention.

Note: Data from the Joint Committee on Infant Hearing. ${ }^{32}$

Abbreviations: $\mathrm{OAE}$, otoacoustic emissions; $\mathrm{AABR}$, automated auditory brainstem response; $\mathrm{ABR}$, auditory brainstem response; NICU, neonatal intensive care unit; WBN, well-baby nursery. 
microphone/receiver to elicit low intensity sounds or OAE generated by the outer hair cells in the cochlea. The test, which simply produces a "pass" or "fail" result, is relatively quick, noninvasive, and does not require sleep or sedation. The recording often takes seconds and can be administered without audiological expertise. One disadvantage with this test is that it is sensitive to peripheral hearing impairment, such as mild conductive hearing loss resulting from debris associated with vernix caseosa and amniotic fluid in the external ear canal, and it is therefore not recommended in the first day of life. The test is also sensitive to excessive internal noise from patient or ambient noise in the test environment and will not detect any retrocochlear dysfunction of the inner hair cells and beyond, such as auditory neuropathy spectrum disorders. DPOAE differs from TEOAE as they are generated by two continuous pure tones introduced to the ear simultaneously and result from the normal nonlinear amplifying process within the inner ear. Because DPOAEs are evoked by frequency-specific signals, it is possible to use the response to predict frequency-specific hearing sensitivity across the range of $500-8,000 \mathrm{~Hz}$.

The auditory brainstem response (ABR) is an electrophysiological measure of the function of the auditory pathway from the eighth cranial nerve through the brainstem. The major advantage of this test is the fact that it is not state-dependent as recordings can be obtained when babies are sleeping or sedated. In addition, the response is significantly correlated with the degree of hearing loss. In general, the click-evoked threshold predicts the behavioral audiometric threshold in the 1,000-4,000 $\mathrm{Hz}$ range within $10-15 \mathrm{dBHL}$. It is therefore valuable as a confirmatory test in infants. The automated version - AABR - is designed specifically for screening purposes to produce a "pass" or "fail/refer" result.

The quality benchmarks for an efficient NHS program include: screening at least $95 \%$ of eligible neonates before hospital discharge or by the age of one month within 6 months of program initiation; the percentage of neonates who fail screening tests and are referred for diagnostic evaluation not exceeding 4\% within the first year of program initiation; at least $70 \%$ of infants requiring diagnostic evaluation return for hearing assessment; and the mean age at which hearing loss is confirmed is 3 months or less. ${ }^{32}$

The core EHDI team of service providers ideally should include primary health care professionals, pediatricians, audiologists, otolaryngologists, speech-language pathologists, and educators of children who are deaf or hard of hearing. Because some of these services may be outsourced, the professionals so engaged must work in consultation with the relevant units in the birthing hospital and the affected families. This team will be complemented typically with other professionals delivering services such as genetics, ophthalmology, developmental pediatrics, service coordination, supportive family education, and counseling. The specific functions recommended for each member of the EHDI team are described in greater detail by $\mathrm{JCIH} .{ }^{32}$ While not charged directly with the actual hearing screening of the child, pediatricians and family physicians are expected to work in partnership with parents and other professionals such as audiologists, otolaryngologists, speech therapists, and educators to ensure seamless delivery of EHDI services for infants identified with hearing loss.

The WHO recognizes that UHS is a worthwhile and attainable goal for all nations, that JCIH guidelines are beneficial for all infants and their families, and that no screen is not an acceptable option. However, it supports interim approaches using targeted screening based on questionnaires, behavioral methods, and/or physiological methods guided by evidence from well conducted pilot studies, especially in LMICs. ${ }^{33}$ This is corroborated by more recent studies on the cost-effectiveness of NHS in the People's Republic of China, which also has vast underdeveloped communities. ${ }^{34,35}$ WHO experts further reiterate that regardless of the approach adopted, the EHDI program should be linked to existing health care, social, and educational systems, and that the procedures and outcomes of the program be documented for effective follow-up. ${ }^{33}$ Additionally, the need to ensure that targeted/selective hearing screening (THS) was based on context-specific risk factors, ideally guided by findings from well conducted pilot UHS programs and other local epidemiological data, is emphasized. ${ }^{36}$

\section{Overview of NHS services in LMICs}

Findings from the literature search show that some forms of NHS have been conducted and reported in ten $(11 \%)$ of the 91 focus countries, ie, Bangladesh, India, Pakistan, Philippines, Côte d'Ivoire, Nigeria, Egypt, Jordan, Cuba, and Guatemala. ${ }^{37-66}$ Although NHS projects have not been reported in the vast majority of the countries, the absence of evidence from this literature search is not necessarily evidence of absence of NHS projects.

India appears to have the most extensive NHS projects based on the number of identified reports. ${ }^{40-50}$ A nationwide roll-out of NHS has also been launched in India under a 
comprehensive program on child health screening and early intervention services for 30 developmental disorders. ${ }^{67,68}$ The program is intended as a collaboration between the central government and the regional health authorities. The services aim to cover all children aged 0-6 years in rural areas and urban slums, in addition to older children up to 18 years of age to ensure a continuum of care for optimal early childhood development. ${ }^{67}$ In the Philippines, legislation was enacted in 2009 to establish UHS program nationwide. ${ }^{69}$ The program set out to institutionalize measures for the prevention and early diagnosis of congenital hearing loss among newborns, the provision of referral follow-up, recall and early intervention services for infants with hearing loss, and counseling and other support services for families of newborns with hearing loss. In Pakistan, one provincial authority has mandated a comprehensive screening program for all newborns in its jurisdiction. ${ }^{70}$ In Nigeria, a pilot UHS program was launched by a private non-governmental organization in partnership with the federal and state government in 2005..$^{54,55}$ This is perhaps the most robust pilot program, comprising two backto-back hospital-based and community-based UHS projects, with almost 11,000 infants enrolled over a 3 -year period. The program was supported with a provision for the early detection for childhood hearing loss in the National Health Policy (2005). The National Ear Care Centre, established in 1999 , was required to provide overall public sector-led initiatives for NHS, among other ear care-related functions. In Cuba, NHS was pioneered as far back as 1983, the oldest program in Latin America and LMICs. ${ }^{62-64}$

The patterns of NHS services in LMICs have remained largely the same as previously reported..$^{71,72}$ In summary, both UHS and THS have been promoted using OAE and/or AABR in hospital and/or community settings. Behavioral or questionnaire-based tests were rarely reported. The vast majority of the projects were hospital-based even in countries with significant numbers of home births. Screening programs rarely met all the JCIH quality benchmarks. Only few countries have federally funded or legislatively backed programs as presently practiced in high-income countries. NHS services were provided by a variety of personnel, including nursing assistants, trained nurses, audiology assistants, audiologists, pediatricians, and otolaryngologists. The choice of screening models and coverage was not uniform, and was largely determined on a case-by-case basis depending on available resources. NHS was rarely considered as a component of comprehensive routine newborn examination by skilled attendants at birth and/or pediatricians before discharge or during the postnatal period..$^{73}$ There was also no evidence to suggest that the decision to introduce NHS services was predicated on cost-effectiveness analyses at the country level, as commonly advocated by donor organizations. ${ }^{74}$ The most prominent challenges reported across available studies can be summarized under two major themes, ie, provision of NHS services and uptake of NHS services.

\section{Challenges to provision of NHS services in LMICs}

The optimal introduction, development, and widespread promotion of NHS services were constrained by the factors outlined in the following sections.

\section{Failure to recognize infant hearing loss as an important health condition}

Global health priorities for newborn care have considerable influence on national health priorities in LMICs, especially among the least developed, which depend heavily on donorfunded programs. It is therefore not surprising that NHS hardly features as an essential child health service in the vast majority of LMICs. Reduction in case fatality was seen more frequently as the end point of successful clinical intervention even for neonatal disorders such as prematurity, birth asphyxia, neonatal sepsis that place survivors at high risk of hearing loss and other developmental disabilities. ${ }^{75}$ Primary care physicians and pediatricians have a considerable influence on families' decisions and compliance with recommendations for child health care, including NHS services. However, medical training curricula rarely include management of hearing impairment, but rather encourage referral to ear, nose and throat specialists for case detection and management. While several reports in both high-income countries and LMICs suggest that physicians were favorably disposed to EHDI, the actual practices showed considerable gaps in knowledge and commitment to NHS services. ${ }^{76-79}$ Because physician consultation is prompted most often by parental suspicion of hearing loss, considerable delay (typically 3-5 years) occurs in the detection of infants with hearing loss. ${ }^{49,80}$ Even when such consultation occurred early, it was not uncommon for parents to be encouraged to wait to confirm that the observed signs were symptoms of a developmental delay rather than an imminent permanent developmental deficit. While the otolaryngologist remains the main referral destination, combining routine hearing screening with the more prestigious and traditional surgical caseloads is not the preference for many otolaryngologists, 
who are very limited in number and by geographical spread in $\mathrm{LMICs}^{81}$

\section{Lack of or inadequate financial resources for NHS services}

The existence of free, well established, and publicly funded health services has been a major catalyst and platform for delivering NHS services in high-income countries. However, many LMICs lack such platforms. Mobilizing human and financial resources specifically for NHS services remains a daunting and almost unattainable goal. Integrating NHS into existing well established child health programs, such as routine immunization, is a possibility that is yet to be fully embraced, partly because it would require the support of the present funders of this global health program in LMICs. ${ }^{82,83}$

Moreover, global priorities mostly favor low-cost interventions. The screening technologies are the most important cost component under any NHS model. Unfortunately, the current hearing screening technologies cannot be viewed as "low-cost" when compared with other widely promoted health interventions in LMICs. For example, a study from Nigeria suggests that it costs between US\$7.62 and US\$73.24 to screen one child in an ideal two-stage screening with OAE and AABR ${ }^{84}$ Another study from India using only AABR estimated the cost of screening per child at approximately US\$4.50. ${ }^{50}$ Inclusive of diagnostic tests, the incremental cost per case detected for the one-stage screening versus two-stage screening protocol in India for example, has been estimated at approximately US\$58,183, while that of a UHS versus THS is estimated at around US $\$ 9,863 .{ }^{85}$ When both $\mathrm{OAE}$ and $\mathrm{AABR}$ are used in combination, they have been found to be most efficient in minimizing false-positives and false-negatives. ${ }^{84}$ However, because the purchase and running costs of OAE instruments are far less expensive than AABR, they are more commonly used and account for high initial referral rates necessitating repeat testing to reduce false-positives.

Screening programs that did not combine OAE and AABR were unable to account for infants with auditory neuropathy spectrum disorders, a form of hearing impairment characterized by a normal peripheral auditory pathway up to the cochlear outer hair cells but with retrocochlear dysfunction. Several studies also highlighted lack of resources for adequate follow-up and effective tracking of infants who failed the screening tests before enrolment in intervention services as a major hurdle in achieving satisfactory performance of NHS programs. ${ }^{37-66}$ Follow-up is a common challenge to
UHS programs worldwide. For example, in the USA, which has the most established UHS programs, care providers were more frequently implicated in poor follow-up of infants who required further evaluation. ${ }^{86,87}$ This problem is exacerbated in LMICs because of poor infrastructural development and inefficient patient data management systems.

\section{Lack of appropriate risk-based selective screening}

While cost and logistical constraints encouraged THS as the starting point for NHS services in LMICs, the factors used to identify eligible infants are poorly understood or described to optimize screening coverage. ${ }^{36}$ Furthermore, not all infants with established risk factors are likely to have hearing loss, which also has implications for the effectiveness of THS depending on the epidemiological profile of each condition in specific countries. For example, the contribution of severe hyperbilirubinemia to the incidence of neonatal hearing loss is likely to be greater in LMICs with a high prevalence of hemolytic disease than in countries with a low prevalence. ${ }^{88,89}$ Even with the present limited knowledge of these factors, high-risk infants are rarely screened by pediatricians or referred routinely to audiologists and otolaryngologists for hearing evaluation.

\section{Unsuitable environment and conditions for hearing tests}

Commercially available models of screening technologies varied in their performance and reliability under different test environments and often accounted for high rates of false-positives. ${ }^{90}$ In particular, some studies have highlighted the difficulties encountered in conducting NHS due to excessive ambient noise, especially in poorly located or very busy hospitals. ${ }^{43,47,65}$ The quest for affordable technologies is therefore commonly associated with some trade-off in screening performance. Some low-cost models recommended for LMICs therefore have limitations that must be recognized in any NHS program. ${ }^{91}$

\section{Cost of intervention services}

A major disincentive to the introduction and promotion of voluntary NHS services is the substantial financial investment required in acquiring and maintaining hearing devices over a lifetime. ${ }^{5,92-94}$ For example, the WHO recommends that the target price for an "affordable" hearing aid should be no more than $3 \%$ of the per capita of the user's country. This amount translates to a maximum of about US\$180 for the eligible LMICs in this paper, and excludes the costs of ear 
molds, maintenance, and the periodic purchase of batteries. This amount is still far beyond the means of the vast majority of families. The scenario is even more daunting for cochlear implants, which are associated with an estimated lifetime cost of about US\$90,000 per child with severe to profound hearing impairment. ${ }^{5}$ For example, in India, with its per capita income of US\$1,570 (2013, World Bank data), cochlear implants are estimated to cost between US\$12,000 and US\$25,000, exclusive of hospital and staff fees. ${ }^{93}$

\section{Challenges to voluntary uptake of NHS services in LMICs}

Several issues were identified from available reports, and are outlined in the following sections.

\section{Sociocultural inhibitions towards persons with hearing loss}

Perhaps the most critical hurdle to parental favorable disposition towards NHS is the widespread stigma associated with hearing impairment in children. ${ }^{95-98}$ Because of deeply entrenched attitudes, cultural beliefs, and historical perceptions of hearing loss in many communities, a child who is born deaf is regarded as a bad omen that may bring misfortune upon the family. For example, within the traditional paradigm, deafness may be attributed to natural causes such as heredity, blood impurities, noise, and poor aural hygiene, or to unnatural causes, including sorcery, spirits, ancestors, and retribution for failure to perform certain cultural rites. ${ }^{96-98}$ Since the arrival of a newborn is both a joyous and an emotion-laden event for parents and the entire family, the idea of screening apparently normal babies for a possible hidden abnormality is not considered desirable by the vast majority of parents and caregivers with normal hearing. Even in settings where favorable maternal views of NHS have been reported, considerable efforts were still required to secure compliance with follow-up appointments.

\section{Poor or inadequate information from health care providers}

Studies have shown that the quality of information received by parents affects their decision regarding NHS services. ${ }^{99}$ NHS services are presently not included in the routine antenatal educational package in LMICs. Even if it were, health workers would themselves need to be trained and convinced of the importance of NHS to ensure that women attending the antenatal clinics received adequate information on this essential service. Poor uptake after the initial failed screening test has also been attributed to minimal or no prompting by screening staff, caregivers not being traceable, and the perception that hearing loss is not life-threatening. ${ }^{43,100}$

\section{Financial and logistical constraints}

Where parents are required to pay for NHS services with or without subsidy, uptake is likely to be poor. Even where NHS and related intervention services are offered at no charge, voluntary uptake by parents could not be guaranteed. While mandatory NHS programs often facilitate high uptake before hospital discharge, financial and logistical challenges frequently undermined optimal compliance with follow-up appointments. ${ }^{99}$ Parents were unlikely to favor NHS programs that required several visits to the hospital after initial screening. Even if NHS services were offered at no charge, they were also unlikely to travel with their newborns, especially over long distances, sometimes in difficult terrain, using a mode of transportation that is uncomfortable and unsafe for the mother and child.

\section{Addressing the challenges to NHS in LMICs}

While the evidence presented in this review was drawn from a limited number of studies performed in just $10 \%$ of the eligible LMICs, the major findings should be fairly generalizable because of similarities in sociocultural and economic contexts. Possible strategies to improve the delivery and uptake of NHS services in LMICs can therefore be summarized as follows.

\section{Provision of NHS services}

Without prejudice to the aforementioned identical challenges, initiating pilot research projects in various hospital and community settings in individual LMICs should be considered as an essential first step in gaining context-specific insights into the best possible approaches for developing NHS services. Subsequent efforts to promote NHS on a wider scale should be under the coordination of a child care specialist with adequate knowledge of public or community health in a multidisciplinary setting. The coordinator must be able to interface effectively with both policy makers and professional colleagues within an ideal EHDI team. ${ }^{32}$ The coordinator must also be an effective advocate for appropriate health, social, and educational policies for children with hearing loss. Ways of integrating EHDI with existing well established child health and school programs should also be explored.

Several reports have suggested that pediatricians and primary care physicians are perhaps better equipped to discharge this role, with appropriate training. ${ }^{76,77,101,102}$ 
The present training curricula for physicians in LMICs geared almost exclusively towards curtailing case fatality are inadequate to ensure their effectiveness in this role without additional focused training. Typical issues to be covered during such training are well documented. ${ }^{101,102}$ Perhaps most crucially, is the need to train physicians to appreciate the value of EHDI to affected families and wider society. This is because of the greater likelihood that a physician will have positive attitudes about referral, if that physician has a strong belief, possibly backed by experience, that a referral for testing of hearing will benefit the patient. ${ }^{102}$ Conversely, any reservations regarding the efficacy of EHDI/NHS (eg, likelihood of false-positives, parental anxiety and stress, and/ or an underestimation of the impact of infant hearing loss on early childhood development and learning), could result in negative attitudes towards referral. Individual members of the team must also recognize the limits of their core competencies in delivering the range of services required to achieve optimal outcomes for the child and a satisfactory experience for the family. While UHS remains the ultimate goal for any effective EHDI program within the framework of JCIH quality benchmarks, ${ }^{32}$ interim and incremental approaches are warranted in the vast majority of LMICs, in line with current WHO recommendations. ${ }^{33}$

As previously noted, in addition to the overarching goal of speech and language development, intervention can also be aimed at achieving improved outcomes in reading and literacy skills while optimizing overall educational achievement with a specific language base. ${ }^{2}$ The program may also seek to establish appropriate family understanding and acceptance of hearing loss, reduce family stress as the child develops, and improve social and emotional development throughout the school years. Educating parents with the aim of curtailing the incidence of child abuse and neglect and acting to promote and preserve the rights of children with disabilities are also worthwhile intervention goals that should be emphasized by caregivers in LMICs.

It is important to recognize that the best of hearing devices, even if provided free, cannot restore or produce normal hearing for infants with sensorineural hearing loss. This realization should motivate all physicians and caregivers to seek ways of curtailing the incidence of avoidable hearing loss, as much as practicable, in the management of common childhood illnesses in LMICs. ${ }^{2,5}$

Securing governmental support at the federal and state levels is valuable in attracting resources to intervention programs for hearing loss, particularly in public hospitals. However, care must be taken in the selection of champions for such programs.
In Nigeria, for example, despite the abundant epidemiological data on the burden of childhood hearing loss and the establishment of a specialized agency for development and promotion of ear care services since 1999, very limited progress has been made in introducing NHS programs nationwide. This situation may be attributable to the quality of leadership in terms of its vision and passion for such a program. ${ }^{5}$

\section{Facilitating parental uptake for NHS services}

Parental uptake is crucial for implementation of an effective NHS program. Maternal education on the importance of EHDI, preferably during the antenatal period and at delivery, needs to be prioritized. This educational effort must take cognizance of the prevailing sociocultural inhibitions faced in each community by parents, most of whom have normal hearing and no prior experience with a hearing-impaired child. The possible trajectory of a child who has been denied the benefits of EHDI should be graphically characterized for parents as much as possible. It is also important to reiterate that the vast majority of infants will pass the screening test and that NHS helps to reassure parents that their child has no detectable hidden congenital abnormality likely to compromise their optimal development in future.

A major area of concern for parents is how to secure useful guidance on the most feasible intervention options within the context of available skills and resources. Appropriate educational programs to address this subject should be offered to parents. Whatever the rehabilitation options (aural or sign language), parental commitment and active participation in the intervention program must be clarified and emphasized. For example, unrealistic expectations regarding the utility of hearing devices in the development of spoken language are common among parents. This may engender considerable frustration and displeasure towards service providers, if not proactively tackled. Testimonials of successful outcomes from other parents and advice on how to cope with the challenges of intervention should be encouraged. The financial and logistical challenges faced by mothers should also be reflected in the design and choice of screening models to minimize these constraints as far as practicable, including the feasibility of the emerging concept of teleintervention. ${ }^{103}$ NHS services should also be considered for coverage in countries with national or community health insurance schemes.

\section{Conclusion}

NHS is an essential component of neonatal care in highincome countries. There are several obstacles to the 
successful introduction, development, and promotion as well as optimum uptake of NHS services in LMICs. However, these challenges are not insurmountable. Pilot projects should be promoted to gain further insights on possible approaches to optimizing the benefits of EHDI in different communities. Pediatricians and primary care physicians have a crucial role in leading multidisciplinary efforts to address these challenges, including facilitating governmental support for NHS in all LMICs.

\section{Acknowledgment}

The author would like to thank the research team at the Center for Healthy Start Initiative for assistance in gathering relevant reports for this paper.

\section{Disclosure}

The author reports no conflicts of interest in this work.

\section{References}

1. Morton CC, Nance WE. Newborn hearing screening - a silent revolution. $N$ Engl J Med. 2006;354:2151-2164.

2. Olusanya BO. Neonatal hearing screening and intervention in resourcelimited settings: an overview. Arch Dis Child. 2012;97:654-659.

3. United Nations Children's Fund. The state of the world's children 2013: children with disabilities. New York, NY, USA; United Nations Children's Fund; 2013. Available from: http://www.unicef.org/gambia/ SOWC_Report_2013.pdf. Accessed March 31, 2015.

4. Stevens G, Flaxman S, Brunskill E, Mascarenhas M, Mathers CD, Finucane M; Global Burden of Disease Hearing Loss Expert Group. Global and regional hearing impairment prevalence: an analysis of 42 studies in 29 countries. Eur J Public Health. 2013;23:146-152.

5. Olusanya BO, Neumann KJ, Saunders JE. The global burden of disabling hearing impairment: a call to action. Bull World Health Organ. 2014;92:367-373.

6. McKellin WH. Hearing impaired families: the social ecology of hearing loss. Soc Sci Med. 1995;40:1469-1480.

7. Niemann S, Greestein D, David D. Helping children who are deaf: family and community support for children who do not hear well Berkeley, CA, USA: The Hesperian Foundation; 2004. Available from: http://pdi.cnotinfor.pt/recursos/Helping_childrenHF2.pdf. Accessed March 31, 2015.

8. Olusanya BO, Ruben RJ, Parving A. Reducing the burden of communication disorders in the developing world: an opportunity for the millennium development project. JAMA. 2006;296:441-444.

9. Ruben RJ. Redefining the survival of the fittest: communication disorders in the 21st century. Laryngoscope. 2000;110(2 Pt 1):241-245.

10. Olusanya BO. Societal impact of bilirubin-induced hearing impairment in resource-limited nations. Semin Fetal Neonatal Med. 2015; 20:58-63.

11. Shield B. Evaluation of the social and economic costs of hearing impairment: a report for Hear-it. London, UK: London South Bank University; 2006. Available from: http://www.hear-it.org/sites/default/ files/multimedia/documents/Hear_It_Report_October_2007.pdf. Accessed February 15, 2015

12. Gaffney M, Eichwald J, Gaffney C, Alam S; Centers for Disease Control and Prevention. Early hearing detection and intervention among infants hearing screening and follow-up survey, United States, 2005-2006 and 2009-2010. MMWR Surveill Summ. 2014;63 Suppl 2:20-26.

13. Thompson RA, Nelson CA. Developmental science and the media: early brain development. Am Psychol. 2001;56:5-15.
14. Shonkoff JP, Richter L, van der Gaag J, et al. An integrated scientific framework for child survival and early childhood development. Pediatrics. 2012;129:e460-e472.

15. Tomblin JB, Oleson JJ, Ambrose SE, Walker E, Moeller MP. The influence of hearing aids on the speech and language development of children with hearing loss. JAMA Otolaryngol Head Neck Surg. 2014;140:403-409.

16. National Institute for Health and Care Excellence. Cochlear implants for children and adults with severe to profound deafness. NICE technology appraisal guidance, TA166, 2009, UK. Available from: http://www.nice.org.uk/guidance/ta166. Accessed March 31, 2015.

17. Pimperton H, Kennedy CR. The impact of early identification of permanent childhood hearing impairment on speech and language outcomes. Arch Dis Child. 2012;97:648-653.

18. Vohr B, Topol D, Girard N, St Pierre L, Watson V, Tucker R. Language outcomes and service provision of preschool children with congenital hearing loss. Early Hum Dev. 2012;88:493-498.

19. Pimperton H, Blythe H, Kreppner J, et al. The impact of universal newborn hearing screening on long-term literacy outcomes: a prospective cohort study. Arch Dis Child. November 25, 2014. [Epub ahead of print.]

20. Stika CJ, Eisenberg LS, Johnson KC, et al. Developmental outcomes of early-identified children who are hard of hearing at 12 to 18 months of age. Early Hum Dev. 2015;91:47-55.

21. Korver AM, Konings S, Dekker FW, et al. Newborn hearing screening vs later hearing screening and developmental outcomes in children with permanent childhood hearing impairment. JAMA. 2010;304: 1701-1708.

22. Grosse SD. Education cost savings from early detection of hearing loss: new findings. Volta Voices. 2007;14:38-40.

23. Colgan S, Gold L, Wirth K, et al. The cost-effectiveness of universal newborn screening for bilateral permanent congenital hearing impairment: systematic review. Acad Pediatr. 2012;12:171-180.

24. Newton V. Benefits of an early identification and diagnosis of permanent bilateral hearing loss. Hearing Balance Commun. 2013;11:91-99.

25. Harrison M, Roush J, Wallace J. Trends in age of identification and intervention in infants with hearing loss. Ear Hear. 2003;24: 89-95

26. Swanepoel D, Störbeck C, Friedland P. Early hearing detection and intervention in South Africa. Int J Pediatr Otorhinolaryngol. 2009;73: 783-786.

27. Sirur GS, Rangasayee R. Age of identification of hearing impairment in Mumbai - a trend analysis. Int J Pediatr Otorhinolaryngol. 2011;75: 1549-1552.

28. Hayes D. Screening methods: current status. Ment Retard Dev Disabil Res Rev. 2003;9:65-72.

29. Watkin PM. Neonatal screening for hearing impairment. Semin Neonatol. 2001;6:501-509.

30. Olusanya BO. Addressing the global neglect of childhood hearing impairment in developing countries. PLoS Med. 2007;4:e74.

31. Olusanya BO, Ogunlesi TA, Slusher TM. Why is kernicterus still a major cause of death and disability in low-income and middle-income countries? Arch Dis Child. 2014;99:1117-1121.

32. American Academy of Pediatrics (AAP), Joint Committee on Infant Hearing (JCIH). Year 2007 position statement: principles and guidelines for early hearing detection and intervention programs. Pediatrics. 2007;120:898-921.

33. World Health Organization. Neonatal and infant hearing screening. Current issues and guiding principles for action. Outcome of a WHO informal consultation held at WHO headquarters, Geneva, Switzerland, November 9-10, 2009. Available from:http://www.who.int/blindness/ publications/Newborn_and_Infant_Hearing_Screening_Report.pdf. Accessed February 15, 2015.

34. Huang LH, Zhang L, Tobe RY, et al. Cost-effectiveness analysis of neonatal hearing screening program in China: should universal screening be prioritized? BMC Health Serv Res. 2012;12:97. 
35. Tobe RG, Mori R, Huang L, Xu L, Han D, Shibuya K. Cost-effectiveness analysis of a national neonatal hearing screening program in China: conditions for the scale-up. PLoS One. 2013;8:e51990.

36. Olusanya BO. Making targeted screening for infant hearing loss an effective option in less developed countries. Int J Pediatr Otorhinolaryngol. 2011;75:316-321.

37. Mannan MA, Choudhury SM, DeyAC, Dey SK, Naher BS, Shahidullah M. Newborn hearing screening: what are we missing? Bangladesh Med Res Counc Bull. 2014;40:1-5.

38. Ali L, Siddiq S, Khan MA, Maqbool S. A hospital-based universal newborn hearing screening programme using transient evoked otoacoustic emission (TEOAE). Pakistan Pediatric J. 2000;24:117-125.

39. Naqqash S, Zaman S, Hamid KA. Early detection of hearing impairment among high-risk neonates. Ann Pak Inst Med Sci. 2013;9:22-25.

40. Mathur NN, Dhawan R. An alternative strategy for universal infant hearing screening in tertiary hospitals with a high delivery rate, within a developing country, using transient evoked oto-acoustic emissions and brainstem evoked response audiometry. J Laryngol Otol. 2007;121: 639-643.

41. Bansal S, Gupta A, Nagarkar A. Transient evoked otoacoustic emissions in hearing screening programs: protocol for developing countries. Int J Pediatr Otorhinolaryngol. 2008;72:1059-1063.

42. Vaid N, Shanbhag J, Nikam R, Biswas A. Neonatal hearing screening the Indian experience. Cochlear Implants Int. 2009;10 Suppl 1: 111-114.

43. John M, Balraj A, Kurien M. Neonatal screening for hearing loss: pilot study from a tertiary care centre. Indian J Otolaryngol Head Neck Surg. 2009;61:23-26.

44. Paul AK. Early identification of hearing loss and centralized newborn hearing screening facility-the Cochin experience. Indian Pediatr. 2011;48:355-359.

45. Kumar S, Mohapatra B. Status of newborn hearing screening program in India. Int J Pediatr Otorhinolaryngol. 2011;75:20-26.

46. Rai N, Thakur N. Universal screening of newborns to detect hearing impairment - is it necessary? Int J Pediatr Otorhinolaryngol. 2013;77:1036-1041.

47. Jewel J, Varghese PV, Singh T, Varghese A. Newborn hearing screening experience at a tertiary hospital in Northwest India. Int J Otolaryngol Head Neck Surg. 2013;2:211-214.

48. Gulati A, Chadha SK. Neonatal hearing screening: otolaryngologist's perspective. Indian Pediatr. 2014;51:174-175.

49. Kumar S, Kolethekkat AA, Kurien M. Challenges in the detection and intervention of childhood deafness: experience from a developing country. Int J Biomed Res. 2015;6:40-45.

50. Gupta S, Sah S, Som T, et al. Challenges of implementing universal newborn hearing screening at a tertiary care centre from India. Indian J Pediatr. February 6, 2015. [Epub ahead of print.]

51. Chiong CM, Dv Llanes EG, Tirona-Remulla AN, Calaquian CM, Reyes-Quintos MR. Neonatal hearing screening in a neonatal intensive care unit using distortion-product otoacoustic emissions. Acta Otolaryngol. 2003;123:215-218.

52. Santos-Cortez RLP, Chiong CM. Cost-analysis of universal newborn hearing screening in the Philippines. Available from: http:// actamedicaphilippina.com.ph. Accessed February 15, 2015.

53. Tanon-Anoh MJ, Sanogo-Gone D, Kouassi KB. Newborn hearing screening in a developing country: results of a pilot study in Abidjan, Côte d'Ivoire. Int J Pediatr Otorhinolaryngol. 2010;74:188-191.

54. Olusanya BO, Wirz SL, Luxon LM. Hospital-based universal newborn hearing screening for early detection of permanent congenital hearing loss in Lagos, Nigeria. Int J Pediatr Otorhinolaryngol. 2008;72: 991-1001.

55. Olusanya BO, Wirz SL, Luxon LM. Community-based infant hearing screening for early detection of permanent hearing loss in Lagos, Nigeria: a cross-sectional study. Bull World Health Organ. 2008;86: 956-963.

56. Okhakhu AL, Ibekwe TS, Sadoh AS, Ogisi FO. Neonatal hearing screening in Benin City. Int J Pediatr Otorhinolaryngol. 2010;74: $1323-1326$
57. Lasisi AO, Onakoya PA, Lasisi TJ, Akinola MD, Tongo O. Neonatal hearing screening in a rural/sub-urban community in Nigeria, subSaharan Africa-a preliminary report. Int $J$ Pediatr Otorhinolaryngol. 2014;78:1452-1455.

58. El-Gamal Y, Hazaa N, Awwad K. Otoacoustic emission in high risk neonates. Egypt J Otolaryngol. 2001;185(1 Suppl):145-155.

59. Kamal N, Kamal R, El-Neikheily I, Hassan D. Neonatal hearing screening: a model for developing countries. Egypt J Pediatr. 2007;24: 495-509.

60. Imam SS, El-Farrash RA, Taha HM, Bishoy HE. Targeted versus universal neonatal hearing screening in a single Egyptian center. ISRN Pediatr. 2013;2013:574937.

61. Attias J, Al-Masri M, AbuKadir L, et al. The prevalence of congenital and early-onset hearing loss in Jordanian and Israeli infants. Int J Audiol. 2006:45:528-536.

62. Pérez-Abalo MC, Gaya Vasquez JA, López GS, González MP, Ponce de León Mola M, Castillo MS. A 25-year review of Cuba's screening program for early detection of hearing loss. MEDICC Rev. 2009;11: 21-28.

63. Centers for Disease Control and Prevention, National Center on Birth Defects and Developmental Disabilities. Early Hearing Detection and Intervention (EHDI) in Latin America. Available from: http://www. cdc.gov/ncbddd/hearingloss/ehdi-latin.html. Accessed February 15, 2015 .

64. Gerner de Garcia B, Gaffney C, Chacon S, Gaffney M. Overview of newborn hearing screening activities in Latin America. Rev Panam Salud Publica. 2011;29:145-152.

65. Aurélio FS, Tochetto TM. Newborn hearing screening: experiences of different countries. Int Arch Otorhinolaryngol. 2010;14:355-363.

66. Krishnan LA, Donaldson LK. Newborn hearing screening in developing countries: understanding the challenges and complexities of implementation. Perspectives on Global Issues in Communication Sciences and Related Disorders. 2013;3:54-61.

67. United Nations Children's Fund. Rastriya Bal Swasthya Karyakram operational guidelines. Available from: http://www.unicef.org/india/7. Rastriya_Bal_Swaasthya_karyakaram.pdf. Accessed February 15, 2015.

68. Singh V. Newborn hearing screening: present scenario. Indian $J$ Community Med. 2015;40:62-65.

69. Republic of the Philippines. An Act establishing a universal newborn hearing screening program for the prevention, early diagnosis and intervention of hearing loss. Republic Act No 9709 August 12, 2009. Available from: http://www.lawphil.net/statutes/repacts/ra2009/ ra_9709_2009.html. Accessed February 15, 2015.

70. Government of Sindh, Pakistan. The Newborn Screening (Sindh) Ordinance 2013. Karachi, Pakistan. Available from: http://www.pas. gov.pk/uploads/downloads/The $\% 20$ Newborn $\% 20$ Screening $\% 20$ (Sindh)\%20Ordinance\%202013.pdf. Accessed February 15, 2015.

71. Olusanya BO, Swanepoel de W, Chapchap MJ, et al. Progress towards early detection services for infants with hearing loss in developing countries. BMC Health Serv Res. 2007;7:14.

72. Olusanya BO, Somefun AO, Swanepoel de W. The need for standardization of methods for worldwide infant hearing screening: a systematic review. Laryngoscope. 2008;118:1830-1836.

73. Green K, Oddie S. The value of the postnatal examination in improving child health. Arch Dis Child Fetal Neonatal Ed. 2008;93: F389-F393.

74. Hutubessy R, Chisholm D, Edejer TT. Generalized cost-effectiveness analysis for national-level priority-setting in the health sector. Cost Eff Resour Alloc. 2003;1:8.

75. Committee on Nervous System Disorders in Developing Countries: Board on Global Health. Developmental disabilities. In: Institute of Medicine, editor. Neurological, Psychiatric and Developmental Disorders: Meeting the Challenge in the Developing World. Washington, DC: National Academy Press; 2001.

76. Dorros C, Kurtzer-White E, Ahlgren M, Simon P, Vohr B. Medical home for children with hearing loss: physician perspectives and practices. Pediatrics. 2007;120:288-294. 
77. Moeller MP, White KR, Shisler L. Primary care physicians' knowledge, attitudes, and practices related to newborn hearing screening. Pediatrics. 2006;118:1357-1370.

78. Olusanya BO, Roberts AA. Physician education on infant hearing loss in a developing country. Pediatr Rehabil. 2006;9:373-377.

79. Rogha M, Mokhtari E. Study of the knowledge of pediatricians and senior residents relating to the importance of hearing impairment and deafness screening among newborns. Iran J Otorhinolaryngol. 2014;26: 57-64.

80. Olusanya BO, Luxon LM, Wirz SL. Childhood deafness poses problems in developing countries. BMJ. 2005;330:480-481.

81. World Health Organization. Multi-country assessment of national capacity to provide hearing care. Geneva, Switzerland: World Health Organization; 2013. Available from: http://www.who.int/pbd/publications/ WHOReportHearingCare_Englishweb.pdf. Accessed February 14, 2015.

82. Olusanya BO. Optimising the use of routine immunisation clinics for early childhood development in sub-Saharan Africa. Vaccine. 2009;27: 3719-3723.

83. Wallace AS, Ryman TK, Dietz V. Experiences integrating delivery of maternal and child health services with childhood immunization programs: systematic review update. J Infect Dis. 2012;205 Suppl 1: S6-S19.

84. Olusanya BO, Emokpae A, Renner JK, Wirz SL. Costs and performance of early hearing detection programmes in Lagos, Nigeria. Trans $R$ Soc Trop Med Hyg. 2009;103:179-186.

85. Burke MJ, Shenton RC, Taylor MJ. The economics of screening infants at risk of hearing impairment: an international analysis. Int J Pediatr Otorhinolaryngol. 2012;76:212-218.

86. Shulman S, Besculides M, Saltzman A, Ireys H, White KR, Forsman I. Evaluation of the universal newborn hearing screening and intervention program. Pediatrics. 2010;126 Suppl 1:S19-S27.

87. Russ SA, Hanna D, DesGeorges J, Forsman I. Improving follow-up to newborn hearing screening: a learning-collaborative experience. Pediatrics. 2010;126 Suppl 1:S59-S69.

88. Olusanya BO, Emokpae AA, Zamora TG, Slusher TM. Addressing the burden of neonatal hyperbilirubinaemia in countries with significant glucose-6-phosphate dehydrogenase deficiency. Acta Paediatr. 2014; 103:1102-1109.

89. Bhutani VK, Zipursky A, Blencowe H, et al. Neonatal hyperbilirubinemia and Rhesus disease of the newborn: incidence and impairment estimates for 2010 at regional and global levels. Pediatr Res. 2013; 74 Suppl 1:86-100.
90. Olusanya BO. Ambient noise levels and infant hearing screening programs in developing countries: an observational report. Int J Audiol. 2010;49:535-541.

91. Ramesh A, Jagdish C, Nagapoorinima M, et al. Low cost calibrated mechanical noisemaker for hearing screening of neonates in resource constrained settings. Indian J Med Res. 2012;135:170-176.

92. McPherson B. Innovative technology in hearing instruments: matching needs in the developing world. Trends Amplif. 2011;15:209-214.

93. Krishnamoorthy K, Samy RN, Shoman N. The challenges of starting a cochlear implant programme in a developing country. Curr Opin Otolaryngol Head Neck Surg. 2014;22:367-372.

94. Chundu S, Manchaiah VK, Stephens D, Kumar N. Parental reported benefits and shortcomings of cochlear implantation: pilot study findings from Southeast Asia. Cochlear Implants Int. 2013;14:22-27.

95. Kiyanga NB, Moores DF. Deafness in Sub-Saharan Africa. Am Ann Deaf. 2003;148:18-24.

96. Stephens D, Stephens R, Eisenhart-Rothe A. Attitudes toward hearing impaired children in less developed countries: a pilot study. Audiology. 2000;39:184-191.

97. Byford J, Veenstra N. The importance of cultural factors in the planning of rehabilitation services in a remote area of Papua, New Guinea. Disabil Rehabil. 2004;26:166-175.

98. Andrade V, Ross E. Beliefs and practices of black South African traditional healers regarding hearing impairment. Int J Audiol. 2005;44 489-499.

99. Scheepers LJ, Swanepoel de W, Roux TI. Why parents refuse newborn hearing screening and default on follow-up rescreening - a South African perspective. Int J Pediatr Otorhinolaryngol. 2014;78: $652-658$

100. Olusanya BO, Akinyemi OO. Community-based infant hearing screening in a developing country: parental uptake of follow-up services. BMC Public Health. 2009;9:66.

101. Mutton PE, Peacock KM. Hearing impaired neonate: role of the paediatrician. J Paediatr Child Health. 2006;42:384-386.

102. Moeller MP, Eiten L, White K, Shisler L. Strategies for educating physicians about newborn hearing screening. J Acad Rehabil Audiol. 2006;39:11-32.

103. McCarthy M, Muñoz K, White KR. Teleintervention for infants and young children who are deaf or hard-of-hearing. Pediatrics. 2010; 126 Suppl 1:S52-S58. 


\section{Supplementary table}

Table SI Eligible low- and middle-income countries (GNI per capita $\leq \$ 6,000$ )

\begin{tabular}{|c|c|c|c|c|c|c|c|c|}
\hline SN & Country & Region & $\begin{array}{l}\text { HDI Rank } \\
2012\end{array}$ & HDI & $\begin{array}{l}\text { Life expectancy } \\
\text { (Years) }\end{array}$ & $\begin{array}{l}\text { GNI per } \\
\text { capita (\$) }\end{array}$ & $\begin{array}{l}\text { Annual } \\
\text { livebirths ('000) }\end{array}$ & $\begin{array}{l}\text { Hospital } \\
\text { delivery (\%) }\end{array}$ \\
\hline I & Afghanistan & SOA & 175 & 0.374 & 49.1 & 1,000 & $\mathrm{I}, 408$ & 33 \\
\hline 2 & Angola & SSA & 148 & 0.508 & 51.5 & 4,812 & 803 & 46 \\
\hline 3 & Armenia & ECA & 87 & 0.729 & 74.4 & 5,540 & 47 & 99 \\
\hline 4 & Bangladesh & SOA & 146 & 0.515 & 69.2 & $\mathrm{I}, 785$ & 3,016 & 29 \\
\hline 5 & Belize & LAC & 96 & 0.702 & 76.3 & 5,327 & 8 & 89 \\
\hline 6 & Benin & SSA & 166 & 0.436 & 56.5 & 1,439 & 356 & 87 \\
\hline 7 & Bhutan & SOA & 140 & 0.538 & 67.6 & 5,246 & 15 & 63 \\
\hline 8 & Bolivia, Plurinational State of & LAC & 108 & 0.675 & 66.9 & 4,444 & 264 & 68 \\
\hline 9 & Burkina Faso & SSA & 183 & 0.343 & 55.9 & 1,202 & 730 & 66 \\
\hline 10 & Burundi & SSA & 178 & 0.355 & 50.9 & 544 & 288 & 60 \\
\hline II & Cambodia & EAP & 138 & 0.543 & 63.6 & 2,095 & 317 & 54 \\
\hline 12 & Cameroon & SSA & 150 & 0.495 & 52.1 & 2,114 & 716 & 61 \\
\hline 13 & Cape Verde & SSA & 132 & 0.586 & 74.3 & 3,609 & 10 & 76 \\
\hline 14 & Central African Republic & SSA & 180 & 0.352 & 49.1 & 722 & 156 & 53 \\
\hline 15 & Chad & SSA & 184 & 0.34 & 49.9 & 1,258 & 511 & 16 \\
\hline 16 & Comoros & SSA & 169 & 0.429 & 61.5 & 986 & 28 & NA \\
\hline 17 & Congo & SSA & 142 & 0.534 & 57.8 & 2,934 & 145 & 92 \\
\hline \multirow[t]{2}{*}{18} & Congo, Democratic & SSA & 186 & 0.304 & 48.7 & 319 & 2,912 & 75 \\
\hline & Republic of the & & & & & & & \\
\hline 19 & Côte d'lvoire & SSA & 168 & 0.432 & 56 & 1,593 & 679 & 57 \\
\hline 20 & Cuba & LAC & 59 & 0.78 & 79.3 & 5,539 & 110 & 100 \\
\hline 21 & Djibouti & MEN & 164 & 0.445 & 58.3 & 2,350 & 26 & 87 \\
\hline 22 & Egypt & MEN & 112 & 0.662 & 73.5 & $5,40 \mathrm{I}$ & 1,886 & 72 \\
\hline 23 & El Salvador & LAC & 107 & 0.68 & 72.4 & 5,915 & 126 & 85 \\
\hline 24 & Eritrea & SSA & 181 & $0.35 \mathrm{I}$ & 62 & 531 & 193 & 26 \\
\hline 25 & Ethiopia & SSA & 173 & 0.396 & 59.7 & 1,017 & 2,613 & 10 \\
\hline 26 & Fiji & EAP & 96 & 0.702 & 69.4 & 4,087 & 18 & NA \\
\hline 27 & Gambia & SSA & 165 & 0.439 & 58.8 & $|, 73|$ & 67 & 56 \\
\hline 28 & Georgia & ECA & 72 & 0.745 & 73.9 & 5,005 & 51 & 98 \\
\hline 29 & Ghana & SSA & 135 & 0.558 & 64.6 & $\mathrm{I}, 684$ & 776 & 67 \\
\hline 30 & Guatemala & LAC & 133 & $0.58 \mathrm{I}$ & 71.4 & 4,235 & 473 & 51 \\
\hline 31 & Guinea & SSA & 178 & 0.355 & 54.5 & 941 & 394 & 39 \\
\hline 32 & Guinea-Bissau & SSA & 176 & 0.364 & 48.6 & 1,042 & 59 & 42 \\
\hline 33 & Guyana & LAC & 118 & 0.636 & 70.2 & 3,387 & 13 & 89 \\
\hline 34 & Haiti & LAC & 161 & 0.456 & 62.4 & $\mathrm{I}, 070$ & 266 & 25 \\
\hline 35 & Honduras & LAC & 120 & 0.632 & 73.4 & 3,426 & 205 & 67 \\
\hline 36 & India & SOA & 136 & 0.554 & 65.8 & 3,285 & 27,098 & 47 \\
\hline 37 & Indonesia & EAP & 121 & 0.629 & 69.8 & 4,154 & 4,331 & 55 \\
\hline 38 & Iraq & MEN & 131 & 0.59 & 69.6 & 3,557 & $\mathrm{I}, \mathrm{I} 44$ & 65 \\
\hline 39 & Jordan & MEN & 100 & 0.7 & 73.5 & 5,272 & 154 & 99 \\
\hline 40 & Kenya & SSA & 145 & 0.519 & 57.7 & $\mathrm{I}, 54 \mathrm{I}$ & 1,560 & 43 \\
\hline 41 & Kiribati & EAP & 121 & 0.629 & 68.4 & 3,079 & 22 & 66 \\
\hline 42 & Kyrgyzstan & ECA & 125 & 0.622 & 68 & 2,009 & $13 \mid$ & 97 \\
\hline \multirow[t]{2}{*}{43} & Lao People's Democratic & EAP & 138 & 0.543 & 67.8 & 2,435 & 140 & 17 \\
\hline & Republic & & & & & & & \\
\hline 44 & Lesotho & SSA & 158 & 0.461 & 48.7 & ।,879 & 60 & 59 \\
\hline 45 & Liberia & SSA & 174 & 0.388 & 57.3 & 480 & 157 & 37 \\
\hline 46 & Madagascar & SSA & 151 & 0.483 & 66.9 & 828 & 747 & 35 \\
\hline 47 & Malawi & SSA & 170 & 0.418 & 54.8 & 774 & 686 & 73 \\
\hline 48 & Mali & SSA & 182 & 0.344 & 51.9 & 853 & 728 & 45 \\
\hline 49 & Marshall Islands & EAP & NA & NA & 72.3 & 4,040 & 27 & 85 \\
\hline 50 & Mauritania & SSA & 155 & 0.467 & 58.9 & 2,174 & 118 & 48 \\
\hline 51 & Micronesia, Federated States of & EAP & 117 & 0.645 & 69.2 & 3,352 & 3 & NA \\
\hline 52 & Moldova, Republic of & ECA & 113 & 0.66 & 69.6 & 3,319 & 44 & 99 \\
\hline
\end{tabular}


Table SI (Continued)

\begin{tabular}{|c|c|c|c|c|c|c|c|c|}
\hline SN & Country & Region & $\begin{array}{l}\text { HDI Rank } \\
2012\end{array}$ & HDI & $\begin{array}{l}\text { Life expectancy } \\
\text { (Years) }\end{array}$ & $\begin{array}{l}\text { GNI per } \\
\text { capita (\$) }\end{array}$ & $\begin{array}{l}\text { Annual } \\
\text { livebirths ('000) }\end{array}$ & $\begin{array}{l}\text { Hospital } \\
\text { delivery (\%) }\end{array}$ \\
\hline 53 & Mongolia & EAP & 108 & 0.675 & 68.8 & 4,245 & 65 & 99 \\
\hline 54 & Morocco & MEN & 130 & 0.591 & 72.4 & 4,384 & 620 & 73 \\
\hline 55 & Mozambique & SSA & 185 & 0.327 & 50.7 & 906 & 889 & 58 \\
\hline 56 & Myanmar & EAP & 149 & 0.498 & 65.7 & $\mathrm{I}, 8 \mathrm{I}$ & 824 & 36 \\
\hline 57 & Namibia & SSA & 128 & 0.608 & 62.6 & 5,973 & 60 & 81 \\
\hline 58 & Nepal & SOA & 157 & 0.463 & 69.1 & 1,137 & 722 & 35 \\
\hline 59 & Nicaragua & LAC & 129 & 0.599 & 74.3 & 2,551 & 138 & 74 \\
\hline 60 & Niger & SSA & 186 & 0.304 & 55.1 & 701 & 777 & 17 \\
\hline 61 & Nigeria & SSA & 153 & 0.471 & 52.3 & 2,102 & 6,458 & 35 \\
\hline 62 & Pakistan & SOA & 146 & 0.515 & 65.7 & 2,566 & 4,764 & 41 \\
\hline 63 & Palestine, State of & MEN & 110 & 0.67 & 73 & 3,359 & 33 & NA \\
\hline 64 & Papua New Guinea & EAP & 156 & 0.466 & 63.1 & 2,386 & 208 & 52 \\
\hline 65 & Paraguay & LAC & 111 & 0.669 & 72.7 & 4,497 & 158 & 82 \\
\hline 66 & Philippines & EAP & 114 & 0.654 & 69 & 3,752 & 2,358 & 44 \\
\hline 67 & Rwanda & SSA & 167 & 0.434 & 55.7 & $\mathrm{I}, 147$ & 449 & 69 \\
\hline 68 & Samoa & EAP & 96 & 0.702 & 72.7 & 3,928 & 4 & 81 \\
\hline 69 & Sao Tome and Principe & SSA & 144 & 0.525 & 64.9 & $\mathrm{I}, 864$ & 5 & 79 \\
\hline 70 & Senegal & SSA & 154 & 0.47 & 59.6 & 1,653 & 471 & 73 \\
\hline 71 & Sierra Leone & SSA & 177 & 0.359 & 48.1 & 881 & 227 & 50 \\
\hline 72 & Solomon Islands & EAP & 143 & 0.53 & 68.2 & 2,172 & 17 & 85 \\
\hline 73 & Somalia & SSA & NA & NA & 51.5 & 150 & 416 & 9 \\
\hline 74 & South Sudan & SSA & NA & NA & NA & NA & NA & NA \\
\hline 75 & Sri Lanka & SOA & 92 & 0.715 & 75.1 & 5,170 & 373 & 98 \\
\hline 76 & Sudan & SSA & $|7|$ & 0.414 & 61.8 & $\mathrm{I}, 848$ & $\mathrm{I}, 447$ & 21 \\
\hline 77 & Swaziland & SSA & $|4|$ & 0.536 & 48.9 & 5,104 & 35 & 80 \\
\hline 78 & Syrian Arab Republic & MEN & 116 & 0.648 & 76 & 4,674 & 466 & 78 \\
\hline 79 & Tajikistan & ECA & 125 & 0.622 & 67.8 & 2,119 & 194 & 88 \\
\hline 80 & Tanzania, United Republic of & SSA & 152 & 0.476 & 58.9 & $\mathrm{I}, 383$ & 1,913 & 50 \\
\hline 81 & Timor-Leste & EAP & 134 & 0.576 & 62.9 & 5,446 & 44 & 22 \\
\hline 82 & Togo & SSA & 158 & 0.459 & 57.5 & 928 & 195 & 67 \\
\hline 83 & Tonga & EAP & 95 & 0.71 & 72.5 & 4,153 & 3 & 98 \\
\hline 84 & Tuvalu & EAP & NA & NA & 67.5 & 5,650 & NA & 93 \\
\hline 85 & Uganda & SSA & 161 & 0.456 & 54.5 & 1,168 & 1,545 & 57 \\
\hline 86 & Uzbekistan & ECA & 114 & 0.654 & 68.6 & 3,201 & 589 & 97 \\
\hline 87 & Vanuatu & EAP & 124 & 0.626 & 71.3 & 3,960 & 7 & 80 \\
\hline 88 & Vietnam & EAP & 127 & 0.617 & 75.4 & 2,970 & 1,458 & 92 \\
\hline 89 & Yemen & MEN & 160 & 0.458 & 65.9 & 1,820 & 940 & 24 \\
\hline 90 & Zambia & SSA & 163 & 0.448 & 49.4 & I,358 & 622 & 48 \\
\hline 91 & Zimbabwe & SSA & 172 & 0.397 & 52.7 & 424 & 377 & 65 \\
\hline
\end{tabular}

Notes: By world regions, 42 (46\%) countries are from Sub-Saharan Africa, 18 (20\%) from East Asia and Pacific, 10 (II\%) from Latin America and Caribbean, 8 (9\%) from Middle East and North Africa, 7 (8\%) from South Asia and 6 (6\%) from Europe and Central Asia. These 91 countries account for $64.2 \%$ of the total annual live births of roughly I 35 million globally, have median institutionalised delivery of 65\% (IQR: 43.8\%-82.8\%) and a median HDI of 0.525 (IQR: 0.436-0.632) compared to 0.878 (IQR: 0.825-0.878) for the 50 most developed countries. The human development index (HDI), is published by the United Nations Development Program (UNDP). It is a robust composite measure of the average achievement in three basic dimensions of human development namely: a long and healthy life (health), knowledge (education) and a decent standard of living (income). World Regions: East Asia and Pacific (EAP), Europe and Central Asia (ECA), Latin America and Caribbean (LAC), Middle East and North Africa (MEN), South of Asia (SOA) and Sub-Saharan Africa (SSA). Data from Olusanya et al.'

Abbreviations: HDI, Human Development Index; GNI, Gross National Income; SN, Serial number.

\section{Reference}

1. Olusanya BO, Ogunlesi TA, Slusher TM. Why is kernicterus still a major cause of death and disability in low-income and middle-income countries? Arch Dis Child. 2014;99:1117-1121. 


\section{Publish your work in this journal}

Research and Reports in Neonatology is an international, peer-reviewed, open access journal publishing original research, reports, editorials, reviews and commentaries on neonatal health. The manuscript management system is completely online and includes a very quick and fair peer-review system. Visit http://www.dovepress.com/testimonials.php to read real quotes from published authors.

Submit your manuscript here: http://www.dovepress.com/research-and-reports-in-neonatology-journal 